\title{
PULMONARY HYPERTENSION IN MITRAL STENOSIS
}

\author{
BY \\ WILLIAM EVANS AND D. S. SHORT \\ From the Cardiac Department of the London Hospital \\ Received January 1, 1957
}

It is known that the pulmonary arterial pressure is raised in many patients with mitral stenosis, and that in a proportion of them the abnormal resistance to the blood flow in the pulmonary arterial bed gives rise to persistent pulmonary hypertension. Although this state, which may influence prognosis and prove important in the selection of patients for surgical treatment, has received some attention, it has not yet been adequately investigated.

In a previous paper (Evans et al., 1957) we described the pulmonary vessels in 11 patients with solitary pulmonary hypertension. Our present paper is concerned with the state of these vessels in patients with mitral stenosis, with the significance of the changes, and with their recognition during life.

The presence of naked-eye changes in the pulmonary arteries in mitral stenosis has long been recognized. Thus, Posselt (1909), reviewing all the cases of pulmonary arteriosclerosis published during the nineteenth century, found that mitral stenosis was responsible for 40 per cent of them. It was Parker and Weiss (1936) who first described the microscopical changes; they examined 23 cases and found severe pulmonary arterial lesions in five of them; these included atheroma complicated by thrombosis in the larger arteries, intimal thickening in the muscular arteries, and concentric cellular proliferation in the arterioles. Larrabee et al. (1949) reported arterial lesions in 18 out of 20 cases of well-established mitral stenosis, and remarked that they were most prominent in vessels of 0.15 to $0.05 \mathrm{~mm}$. diameter. In neither of these investigations were the histological changes related to the presence or absence of pulmonary hypertension. Henry (1952) described the presence of an abnormal muscular coat in the arterioles in 40 per cent of 105 cases of mitral stenosis, but he found it in none of 70 control cases. This abnormality has also been reported by Soulié et al. (1953) and Heath and Whitaker (1955) have emphasized its association with pulmonary hypertension.

Almost all workers are agreed that the walls of many of the muscular arteries in mitral stenosis appear abnormally thick and have described the change as medial hypertrophy. O'Neal et al. (1955) undertook a special study of the media of the small muscular pulmonary arteries in 67 cases of moderate or severe mitral stenosis whose average age was 55 years, and compared the findings with those in a control series of comparable age without heart disease. They selected for measurement muscular arteries that were situated near a bronchiole and in order to avoid the discrepancy introduced by variation in the degree of arterial contraction, they calculated the area of the media at each cross-section of the vessel. By this method they failed to demonstrate any significant difference in the amount of arterial media in the two series, and they concluded that although the arteries were smaller there was no medial hypertrophy. They were also unable to identify a medial coat in the arterioles.

The relationship between the vascular changes and the presence of pulmonary hypertension has not yet been resolved. Several workers have tried to correlate arterial changes found on lung 
biopsy or at necropsy with observations made during cardiac catheterization. The amount of lung available for scrutiny is small, however, and single records of the pulmonary arterial pressure are unreliable. Moreover, the diagnosis of pulmonary hypertension should not rest on such evidence, but on clinical, electrocardiographic, and radiological examination.

Apart from the nature of the vascular changes there is the further problem of their extent. This cannot be determined by the examination of discrete histological sections, for these do not provide adequate information on the state of the arterial bed as a whole. Goodwin et al. (1952) recorded pulmonary arteriograms in patients with mitral stenosis, and demonstrated abrupt narrowing of the peripheral arteries in those with severe pulmonary hypertension. Although such an investigation is informative, the authors were aware that it could not distinguish between structural arterial narrowing and arterial spasm whether due to mitral stenosis or provoked by the contrast medium. Pulmonary arteriography at necropsy (Evans, 1951; Short, 1956) is the best means of demonstrating the site, the severity, and the extent, of organic disease affecting the pulmonary vasculature.

\section{The INVESTIGATION DesCRIBED}

A routine clinical, electrocardiographic, and radiological examination of the chest, was made in 24 patients in whom mitral stenosis was confirmed at necropsy, special attention being paid to the diagnosis of pulmonary hypertension. Thirteen were women and eleven men. The ages varied from 16 to 69 , and the average age was 44 years.

At necropsy, the heart was weighed, and the degree of right ventricular hypertrophy was

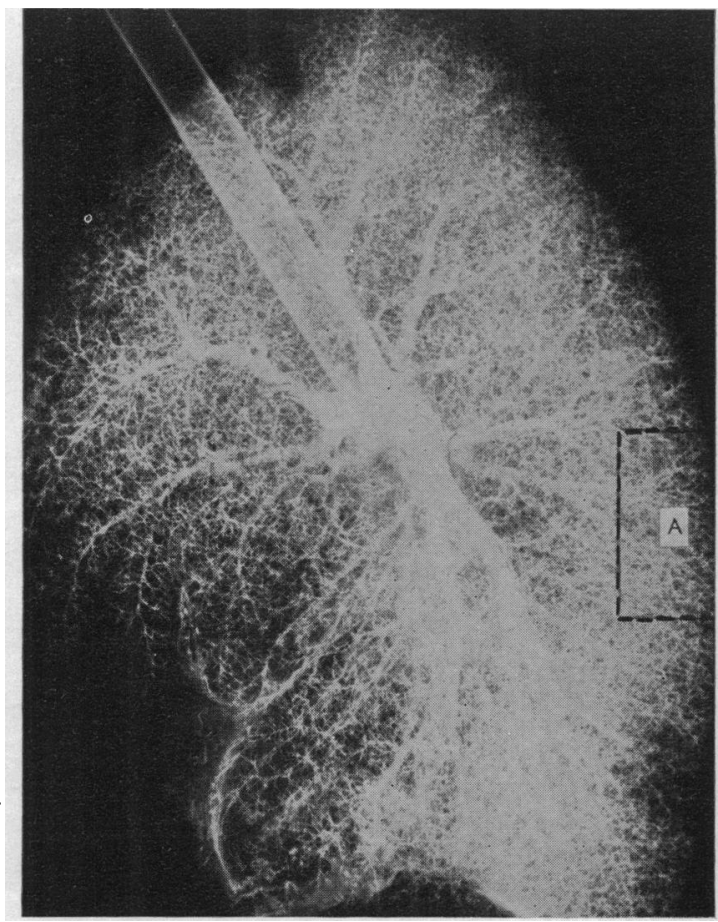

FIG. 1.-Pulmonary arteriogram from a patient with mitral stenosis without pulmonary hypertension. Apart from two filling defects from thrombotic occlusion the peripheral vessels are normal. Segment (A) has been magnified in Fig. 3A.

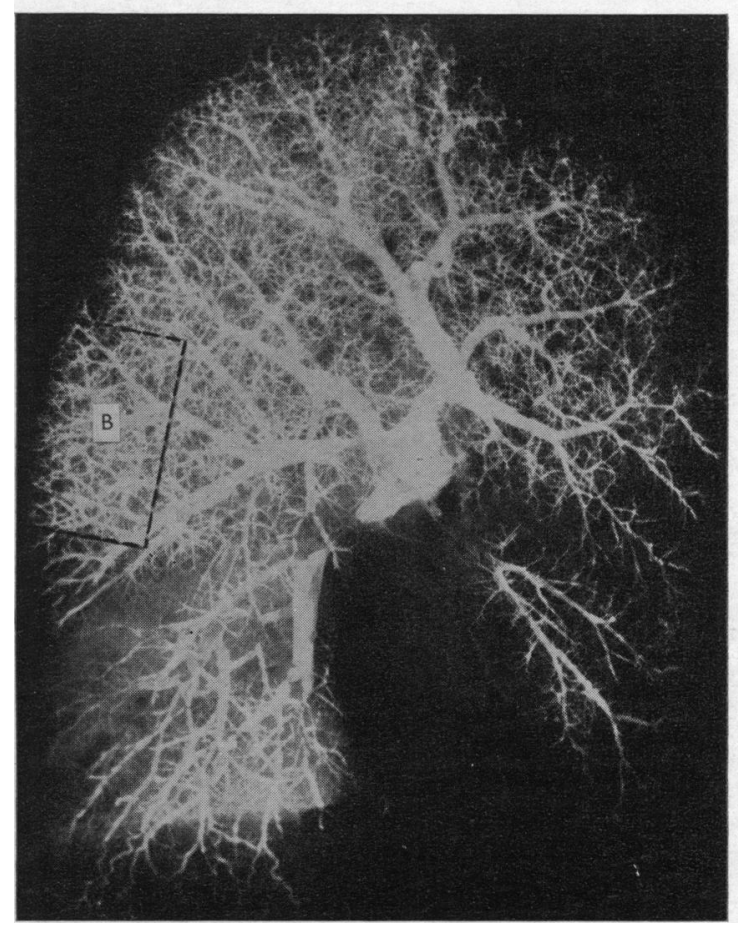

Fig. 2.-Pulmonary arteriogram from a patient with mitral stenosis and pulmonary hypertension. The basal artery and several smaller ones are obstructed by thrombus, but the generalized loss of the finest branches has much greater significance. Segment (B) has been magnified in Fig. 3B. 
estimated by measuring the thickness of its wall and comparing it with that of the left ventricle. The size of the mitral valve orifice was also determined.

The lungs were examined according to the procedure described in our paper on solitary hypertension (Evans et al., 1957). A pulmonary arteriogram was performed in 12 of the cases. A detailed histological examination was made in all, an average of five blocks of lung tissue being taken including sections from an upper and a lower lobe.

\section{The Pulmonary Vascular Changes}

Naked-eye examination of the pulmonary arterial trunk and its main branches revealed dilatation, atheroma, and thrombosis or embolism, but the changes specifically related to pulmonary hypertension came to light only when the finest arteries were examined by a combination of pulmonary arteriography and histology.

\section{The Pulmonary Arteriogram}

The arteriogram was abnormal in each of the 12 cases in which it was carried out. The changes were of two kinds, focal and diffuse. The focal changes, present in every case, included thrombotic obstruction of segmental arteries, especially those to the lower lobes, areas of infarction, and abnormal anastomoses between branches of the pulmonary artery and between bronchial and pulmonary arteries. The diffuse changes, present in 6 of the 12 cases, consisted of an absence of

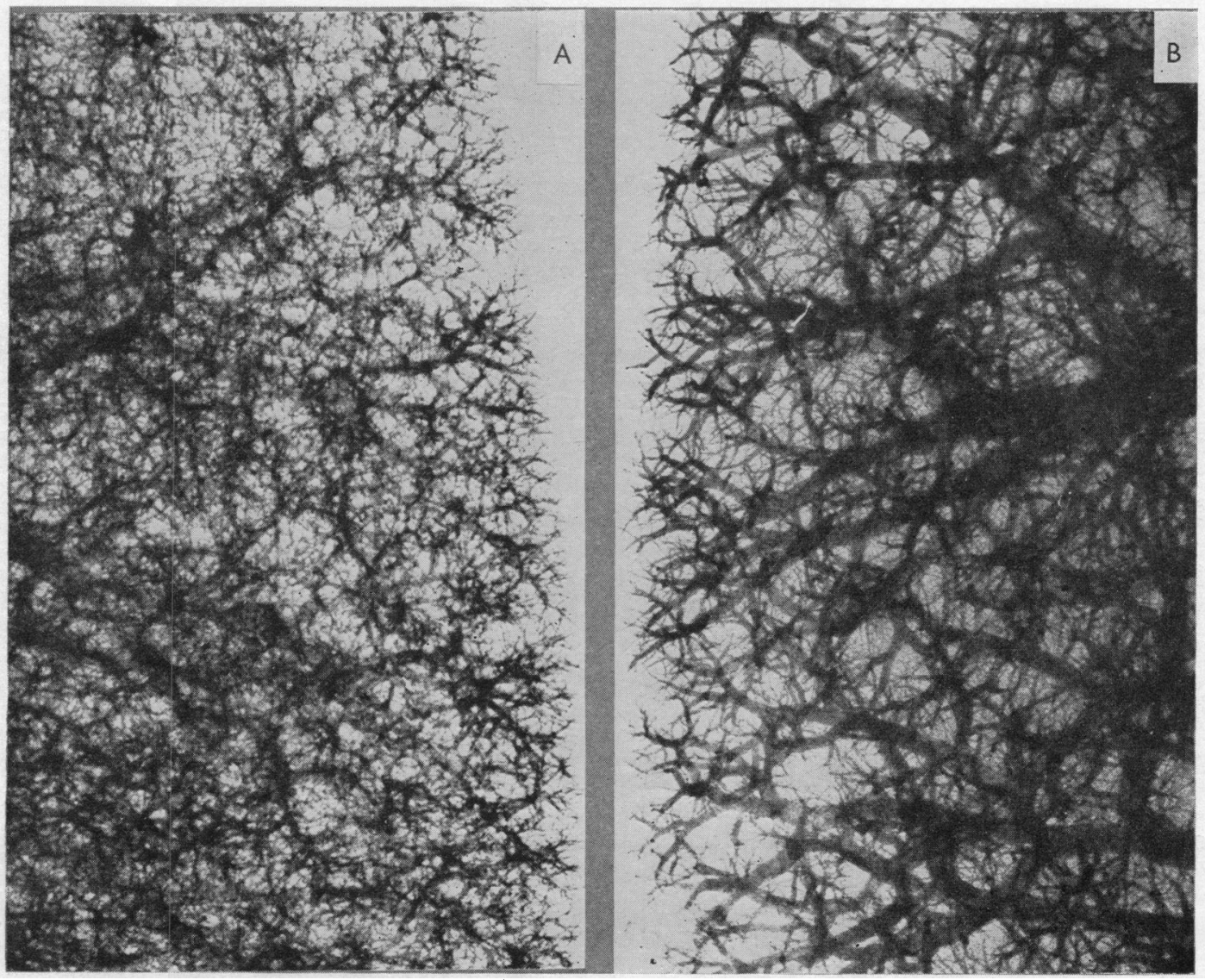

FIG. 3.-Magnified pulmonary arteriogram; (A) is from arteriogram shown in Fig. 1, and (B) from Fig. 2. 


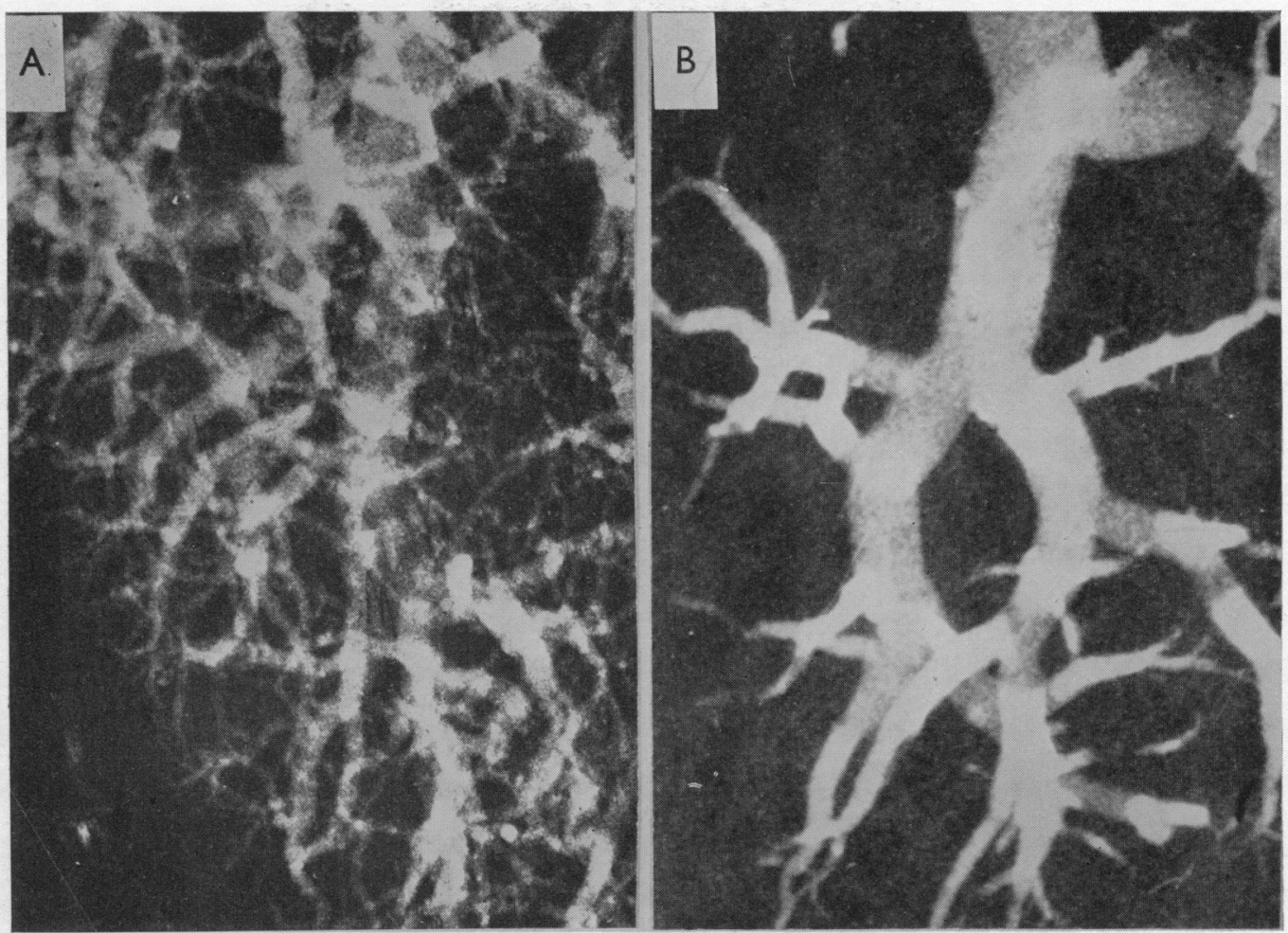

FIG. 4.-Magnified pulmonary arteriograms. (A) is from a patient with mitral stenosis without pulmonary hypertension. (B) is from a patient with mitral stenosis and pulmonary hypertension.

opaque material from the finest branches throughout the lungs. This denuded appearance could be seen in arteriograms of the whole lung (Fig. 2), but was more noticeable in magnified films (Fig. 3A and $\mathrm{B}$ and 4A and B), or in contact prints of lung sections, $1.0 \mathrm{~cm}$. thick (Fig. 5); it was even obvious on inspection of the cut surface (Fig. 6). The lost branches were mostly of arteriolar size. Arteries greater than $0.1 \mathrm{~mm}$. diameter were also sometimes occluded, and even when patent they were frequently smaller in calibre than the corresponding arteries from normal lungs or from cases of mitral stenosis showing only focal changes. The segmental arteries to the lower half of the lung were also constricted; the bore of these narrowed arteries was sometimes smooth, but in other instances atheromatous plaques caused indents in the stream of injected material.

\section{The Histological Changes}

The vascular changes found on histological examination corresponded with those observed in the arteriogram, and were likewise of two kinds, namely subsidiary and salient.

The subsidiary changes were common to all 24 cases. Thus, there was intimal thickening in the elastic arteries in excess of that met with in subjects of a comparable age with normal lungs. There was thrombosis of one or more segmental arteries and even of the pulmonary arterial trunk in two cases. The bronchial arteries in their extra-pulmonary course were normal, but the opaque medium invariably flowed from these vessels during injection of the pulmonary artery, indicating the presence of abnormal broncho-pulmonary arterial anastomoses; there was often a plethora of bronchial arteries within the lung. The capillaries were frequently compressed by thickening of the alveolar septa. The venules were narrowed by the presence beneath the intima of an acellular eosinophilic material (Fig. 7). Thrombosis in the large pulmonary veins was met with in a few instances. 


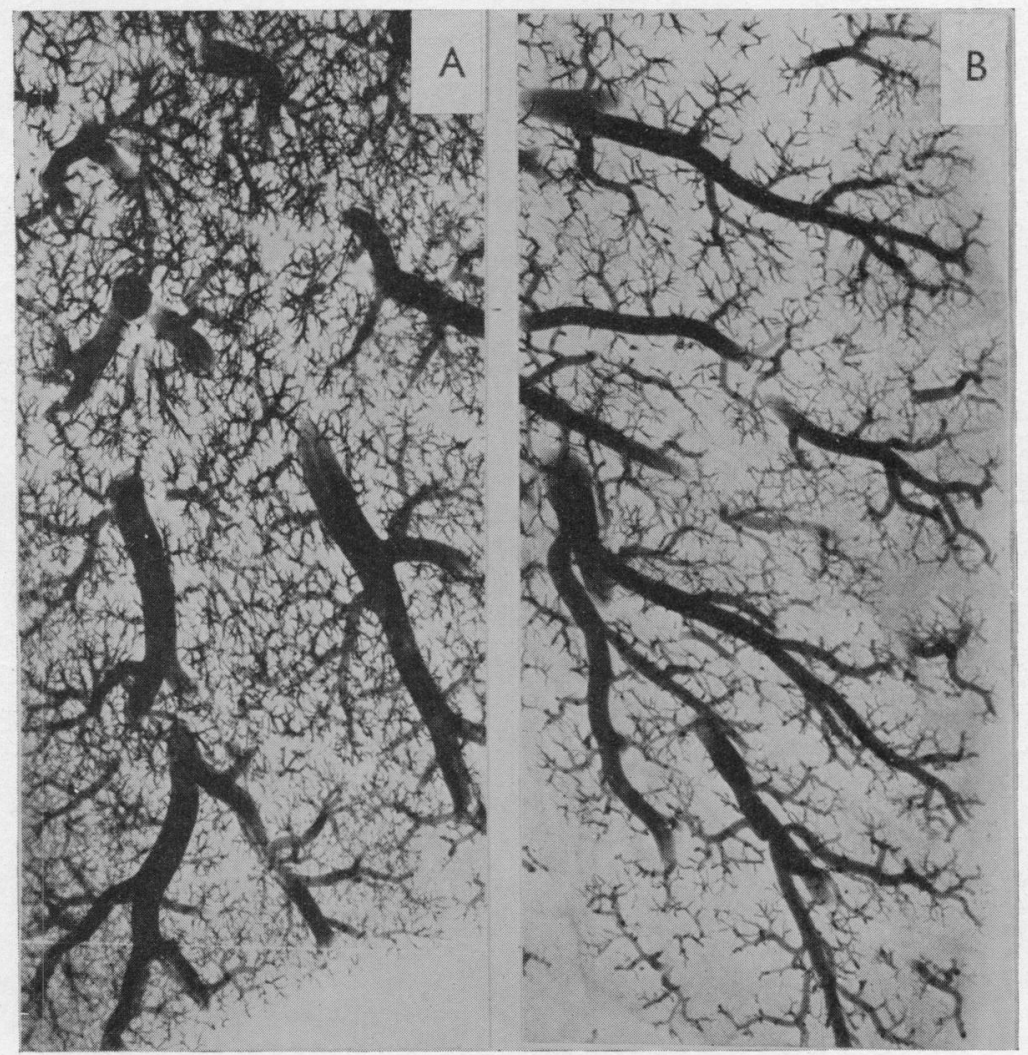

FIG. 5.-Arteriogram of section of lung $1 \mathrm{~cm}$. thick. (A) is from a patient with uncomplicated mitral stenosis. (B) is from a patient with mitral stenosis and pulmonary hypertension.

The salient changes, found in 12 of the 24 patients, were of two kinds. The one was great and widespread intimal proliferation and the other was refractory arterial contraction. The combination of the two processes had led to both narrowing and occlusion of arterioles and small muscular arteries throughout the lung. Whenever an arteriogram had been carried out, it always demonstrated the diffuse changes indicating obstruction of the smaller vessels.

The finding of a few contracted arteries, or the presence of slight and localized intimal proliferation, did not qualify a case for inclusion among those with salient changes, for contracted arteries were found in two cases without important intimal proliferation, and it is known that slight intimal thickening may be found in otherwise normal lungs (McKeown, 1952). Localized intimal proliferation usually gave the impression that it had been thrombotic in its inception.

The presence in vessels of arteriolar size of a distinct muscular coat lying between two elastic layers was a feature of all the twelve cases with salient changes. This change was frequently present in vessels of $0.07 \mathrm{~mm}$. diameter, and occasionally in ones as small as $0.04 \mathrm{~mm}$. (Fig. 8). We regard these, not as " muscularized" arterioles, but as muscular arteries in an abnormal state of contraction. In each of these cases the media of the slightly larger muscular arteries appeared unusually thick, and although this has generally been interpreted as evidence of hypertrophy, we regard it as evidence of refractory arterial contraction.

Intimal proliferation was always severe in the arterioles and gave rise to a characteristic appearance. Thus, layers of endothelial cells with their elongated nuclei were arranged concentrically in 

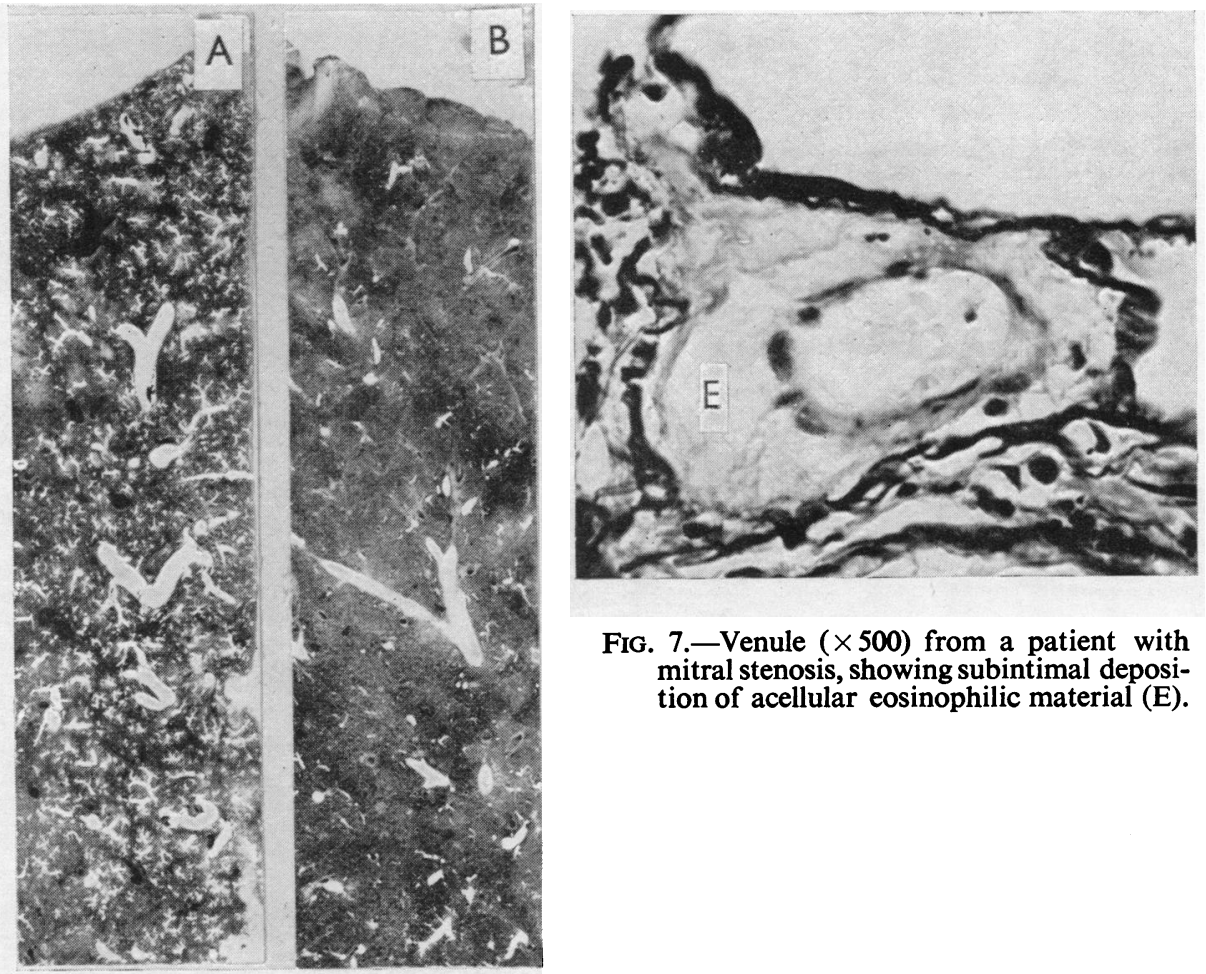

Fig. 7.-Venule $(\times 500)$ from a patient with mitral stenosis, showing subintimal deposition of acellular eosinophilic material (E).

Fig. 6.-Cut-section of injected lung. (A) is from a patient with uncomplicated mitral stenosis. (B) is from a patient with mitral stenosis and pulmonary hypertension.

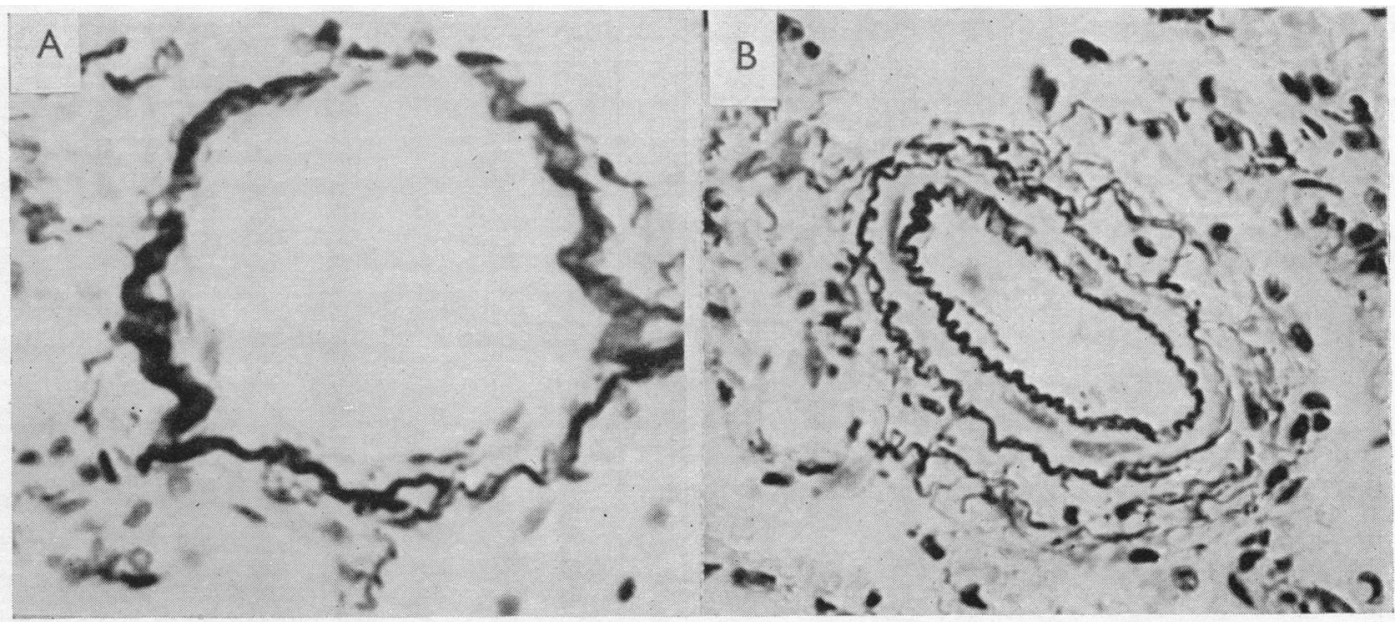

Fig. 8.-Contracted small muscular pulmonary artery $(B)(\times 500)$ from a patient with mitral stenosis and pulmonary hypertension, compared with a normal arteriole $(A)(\times 500)$ from a patient with uncomplicated mitral stenosis. 
a whorl-fashion and the nuclei of the innermost layer were often disposed radially giving rise to a pallisading effect (Fig. 9). In one case there was widespread arteriolar necrosis.

In four of the twelve there was extensive intimal proliferation in the small muscular arteries as well as in the arterioles, and in these vessels the intimal thickening was associated with hypoplasia of the media (Fig. 10). This deficiency usually affected only a segment of the vessel wall, but occasionally the entire media was lost giving the impression of an arteriole. Such deficiencies were also present, though less frequently, in the eight cases where the intimal proliferation affected the arterioles more than the small muscular arteries.

\section{Changes IN THE HearT}

The heart was always heavier than normal. In those with salient pulmonary vascular changes the weight varied between $340 \mathrm{~g}$. and $675 \mathrm{~g}$. with a mean of $470 \mathrm{~g}$., compared with $300 \mathrm{~g}$. as the upper limit of normal. In those with only subsidiary vascular changes, the weight varied between $350 \mathrm{~g}$. and $980 \mathrm{~g}$. with a mean of $620 \mathrm{~g}$. The heaviest hearts were those from patients with associated aortic valve disease.

Hypertrophy of the right ventricle was significantly greater in cases with salient pulmonary vascular changes than in those showing only subsidiary changes. Thus, in the first group, the maximum thickness of the free wall of the ventricle ranged from 6 to $13 \mathrm{~mm}$. with a mean of $9 \mathrm{~mm}$., while in the second group it ranged from 3 to $8 \mathrm{~mm}$. with a mean of $5 \mathrm{~mm}$. In cases with right ventricular hypertrophy, there was usually dilatation and hypertrophy of the right auricle as well. Intracardiac thrombosis was present in six of the cases with salient pulmonary vascular changes, involving the left auricle in five (mass thrombus in two), the right auricle in one and the left ventricle in one. In the group with subsidiary changes, thrombosis was present in eight cases, involving the left auricle in eight (mass thrombus in one), the right auricle in one, and the left ventricle in one.

There was no correlation between the incidence of salient pulmonary arterial disease and the size of the mitral orifice. A reasonably accurate estimate of the size of the opening could be made in 20 of the 24 cases. In 10 of these, with salient vascular changes, the stenosis was severe $(15 \mathrm{~mm}$. or less in length) in 9: in the tenth the mitral orifice was $25 \mathrm{~mm}$. long and $8 \mathrm{~mm}$. wide with heavy calcification of the valve; although there must have been obstruction to the blood flow in this case, the presence of considerable left ventricular hypertrophy indicated substantial mitral incompetence. In the 10 patients with subsidiary vascular changes, the stenosis was severe in 7 and moderately severe (18 to $25 \mathrm{~mm}$. in length) in 3: the most severe stenosis (6 mm. by $4 \mathrm{~mm}$.) in the entire series was found in one of these cases in whom the right ventricle was only $4 \mathrm{~mm}$. thick.

\section{The Diagnosis of Pulmonary Hypertension when Associated with Mitral Stenosis}

Having established by pulmonary arteriography and histological examination, the relationship between specific changes in the lesser pulmonary arteries and the occurrence of pulmonary hypertension in mitral stenosis, we now compare the clinical features in the 12 cases showing salient pulmonary arterial changes and pulmonary hypertension, with those presented by the 12 cases showing only subsidiary pulmonary arterial changes without pulmonary hypertension.

Age. The patients with pulmonary hypertension became disabled at a younger age than those without. Thus, the age at death ranged from 16 to 48 with a mean of 35 years in the first group, compared with 38 to 69 with a mean of 52 years in the second group, even though aortic valve disease also was present in 7 of them.

Sex. Of the 12 patients with pulmonary hypertension, nine were women, compared with four women among the 12 without pulmonary hypertension.

Physical Signs. The presence of pulmonary hypertension in mitral stenosis supplies its own characteristic signs which include a small pulse, raised venous pressure, a prominent auricular wave in the neck if sinus rhythm is present, predominant right ventricular pulsation, a loud pulmonary second sound, a sound in early systole, and occasionally a Graham Steell murmur. 


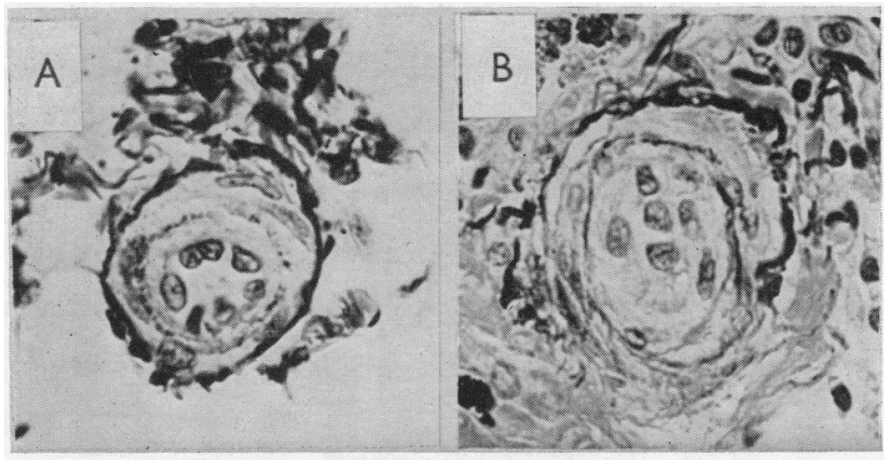

FIG. 9.-Arterioles $(\times 500)$, partly closed in $(A)$ and wholly closed in (B) by intimal proliferation, from two patients with mitral stenosis and pulmonary hypertension. The pallisading appearance in (A) is characteristic.

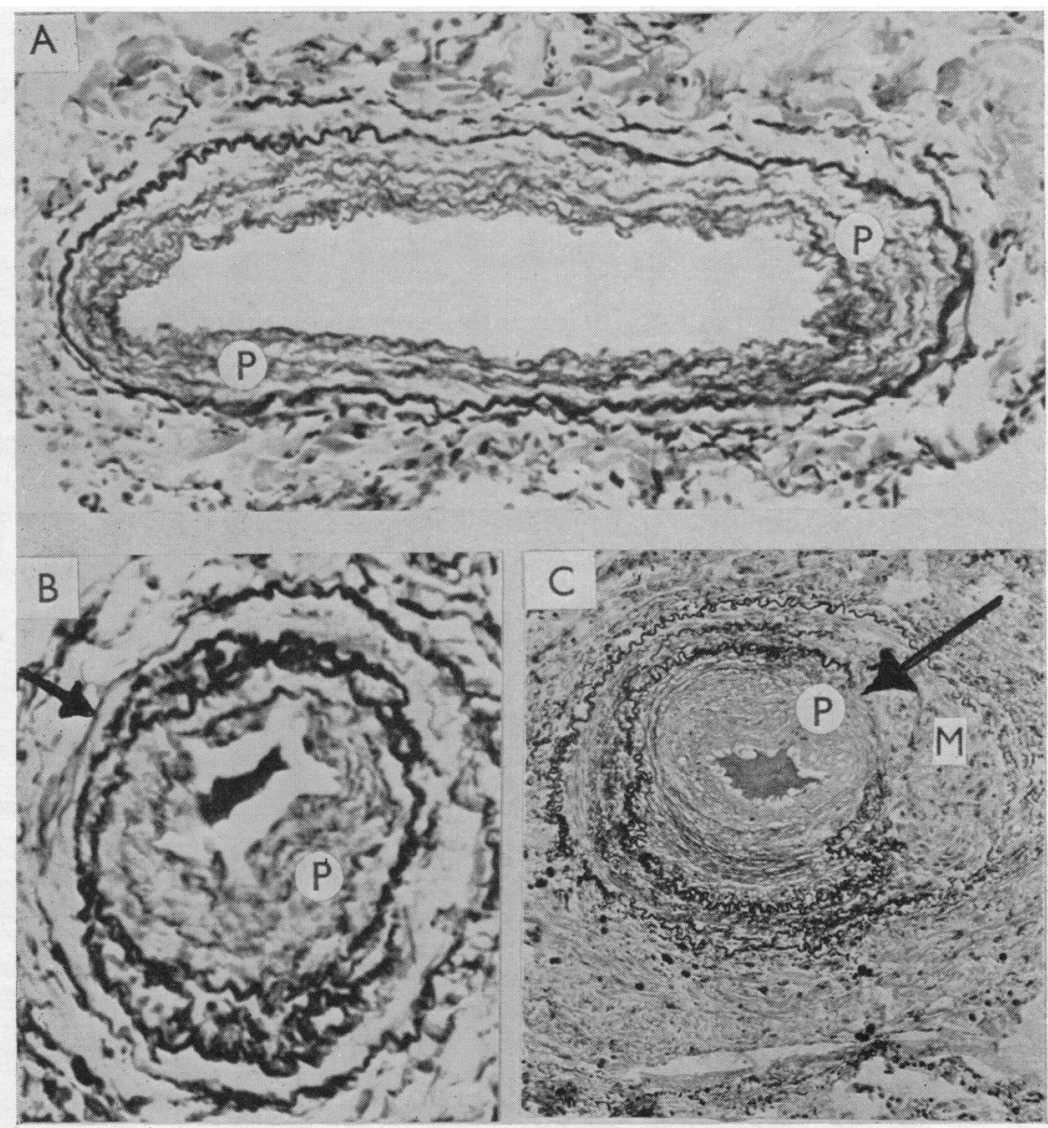

Fig. 10.-Small muscular pulmonary arteries in three patients with mitral stenosis and pulmonary hypertension, showing intimal proliferation $(\mathrm{P})$. In (A) $(\times 200)$ there is general medial hypoplasia especially at the base of the picture. In $(B)(\times 300)$ the site of the medial hypoplasia is indicated by the arrow (top left-hand corner). In (C) $(\times 100)$ a break in the internal elastic layer is indicated by the arrow; the intimal reaction here may be thrombotic in origin. Adjacent to this is an area of medial necrosis (M). 
The Electrocardiogram. The electrocardiogram showed right ventricular preponderance (Fig. 11 and 12) in each of the 12 patients in whom salient pulmonary arterial changes were found on arteriographic and histological examination. Thus, in $\mathrm{CR}_{1}$ or $\mathrm{V}_{1}$ the $\mathrm{R}$ wave was greater than the $S$ in every case; the $S$ was only slightly smaller than $R$ in three, diminutive in four, and absent in five. Whenever $\mathrm{V}_{4} \mathrm{R}$ was recorded it confirmed the right ventricular preponderance. An $\mathrm{S}$ wave was always present in lead $I$; it equalled the $R$ wave in three, and exceeded it in nine cases. An $\mathrm{S}$ wave was present in $\mathrm{CR}_{7}$ in all save three patients, and the $\mathrm{R}$ wave was never tall in this lead. S-T depression was always obvious in lead III, and also in a lesser degree in lead II, though in many patients this deformity was exaggerated by digitalis therapy. The $T$ wave in $\mathrm{CR}_{1}$ or $\mathrm{V}_{1}$ was inverted in the seven patients with normal rhythm; in the remaining five its direction could not be told because of the fibrillation waves.
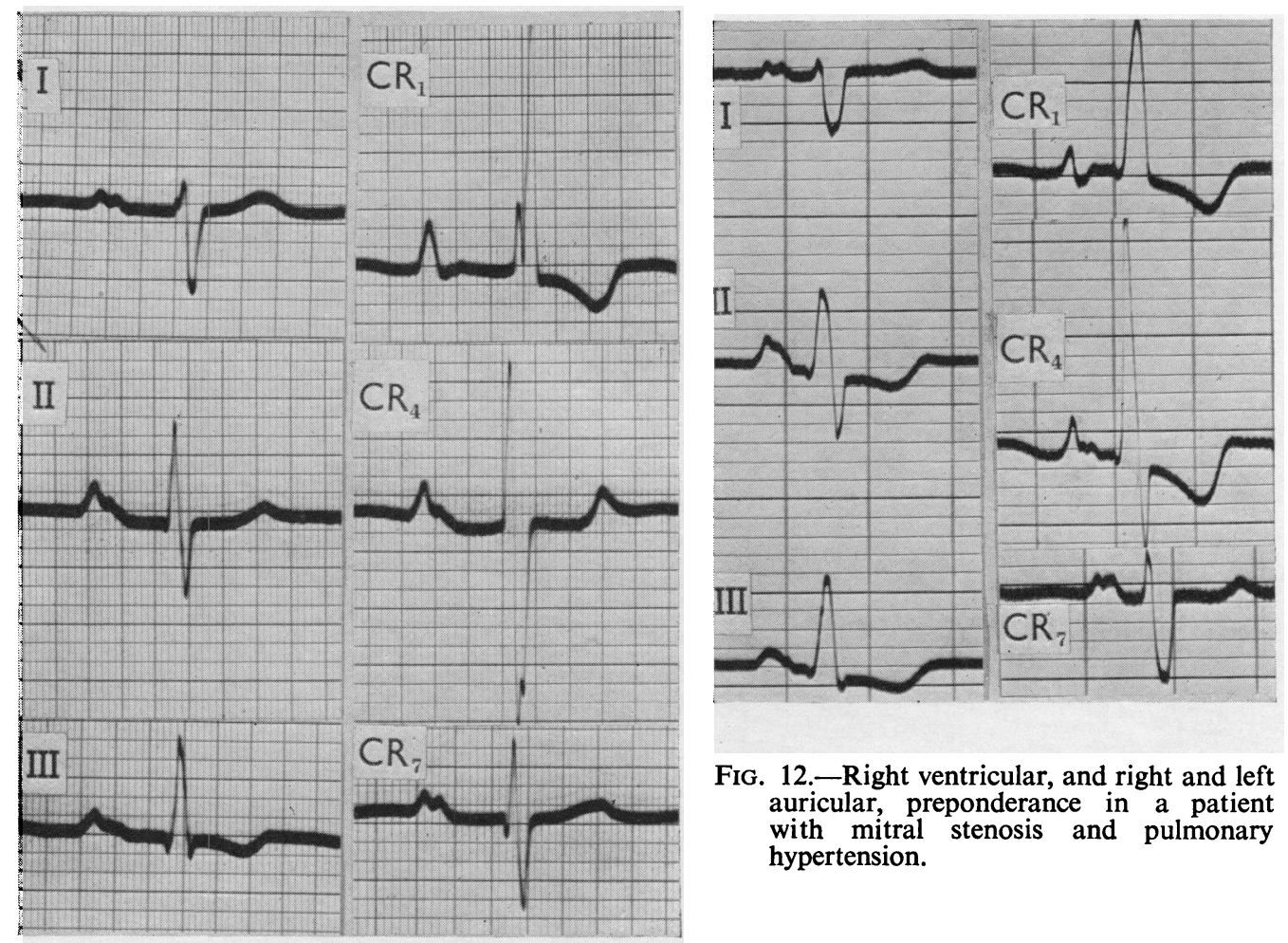

FIG. 12.-Right ventricular, and right and left auricular, preponderance in a patient with mitral stenosis and pulmonary hypertension.

FIG. 11.-Right ventricular, and right and left auricular, preponderance in a patient with mitral stenosis and pulmonary hypertension. Both here and in Fig. 12 the horizontal lines indicate a voltage of $2 \mathrm{~mm}$.

In the patients with mitral stenosis who showed only subsidiary changes in the pulmonary arteries these signs of right heart preponderance were absent. An S wave was never found in $\mathrm{CR}_{7}$ in this group and was present in lead $\mathrm{I}$ in only one half of them. In one the $\mathrm{R}$ wave did just exceed the $S$ in $C_{1}$, but there was no $S$ in either lead $I$ or $C_{7}$.

A $P$ wave that is $2.5 \mathrm{~mm}$. high in $\mathrm{CR}_{1}$ and at the same time diphasic, pointed, or bifid with a dominant first peak indicates right auricular preponderance and supports the diagnosis of pulmonary hypertension in mitral stenosis. Among our seven patients with mitral stenosis and pulmonary hypertension, who had remained in sinus rhythm, electrocardiographic evidence of right auricular preponderance was present in four. 
This correlation between the histological and electrocardiographic changes emphasizes the importance of the electrocardiogram in the diagnosis of pulmonary hypertension in mitral stenosis.

Radiology. In the patients in whom mitral stenosis was associated with pulmonary hypertension, the heart usually appeared somewhat smaller than in those without hypertension, the majority of whom had aortic valve disease as well. Thus, in the first group the width of the heart in proportion to that of the chest ranged from 48 to 77 per cent with a mean of 60 per cent, compared with 54 to 74 per cent with a mean of 67 per cent in the second group.

A distinctive feature of the 12 cases with pulmonary hypertension was the prominence of the pulmonary trunk and its two branches. Although the pulmonary bay was partly or completely filled in the 12 cases without pulmonary hypertension (Fig. 13), in those with hypertension there was usually an actual bulge in the region of the pulmonary artery and the origin of its left branch. The segmental branches were narrow in four patients, probably narrow in one, natural in four, and obscured in the remaining three. In three patients the lung parenchyma appeared abnormally clear as in solitary pulmonary hypertension (Fig. 14), but in six there was conspicuous hilar and pulmonary clouding with distinct interlobular lines, changes characteristic of the indurated lung of mitral stenosis (Short, 1955) (Fig. 15). There was intense hæmosiderosis in one case (Fig. 16).

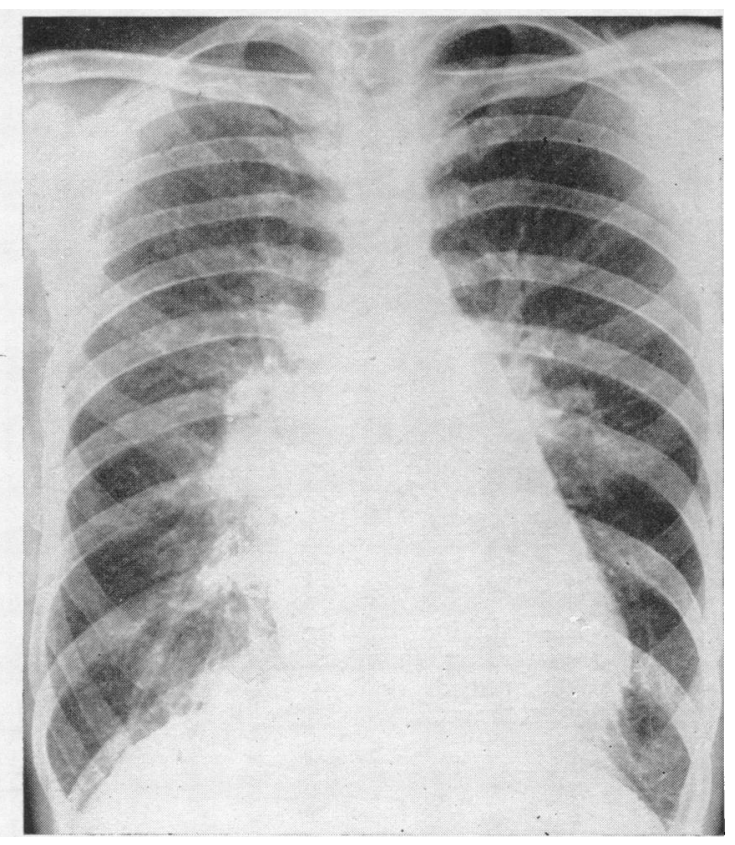

FIG. 13.-Uncomplicated mitral stenosis.

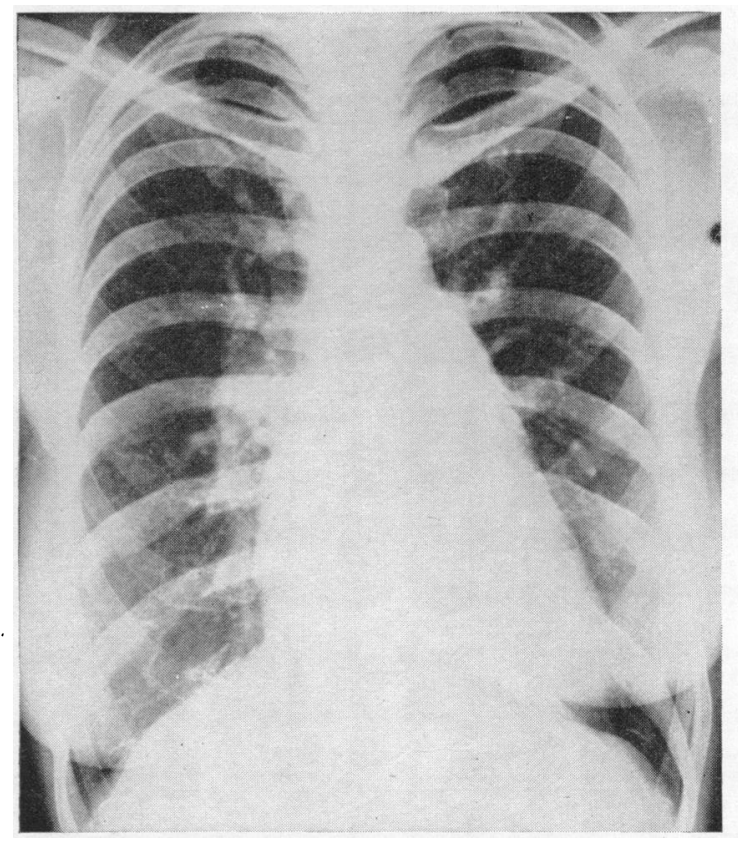

FiG. 14.-Mitral stenosis and pulmonary hypertension. It differs from Fig. 13 only in showing clearer lungs in the periphery.

Cardiac Catheterization. In all cases of significant mitral stenosis the pulmonary arterial pressure, and especially the pulmonary capillary venous pressure, is raised; the pulmonary vascular resistance is slightly increased, and the cardiac output diminished. When pulmonary hypertension is added, the pulmonary arterial pressure and the pulmonary vascular resistance are disproportionately raised, while the cardiac output is further reduced.

The Diagnosis of Mitral Stenosis when Associated with Pulmonary Hypertension

It is sometimes very difficult to recognize mitral stenosis when combined with pulmonary hypertension because the characteristic physical signs of the valvular lesion may be suppressed. A 


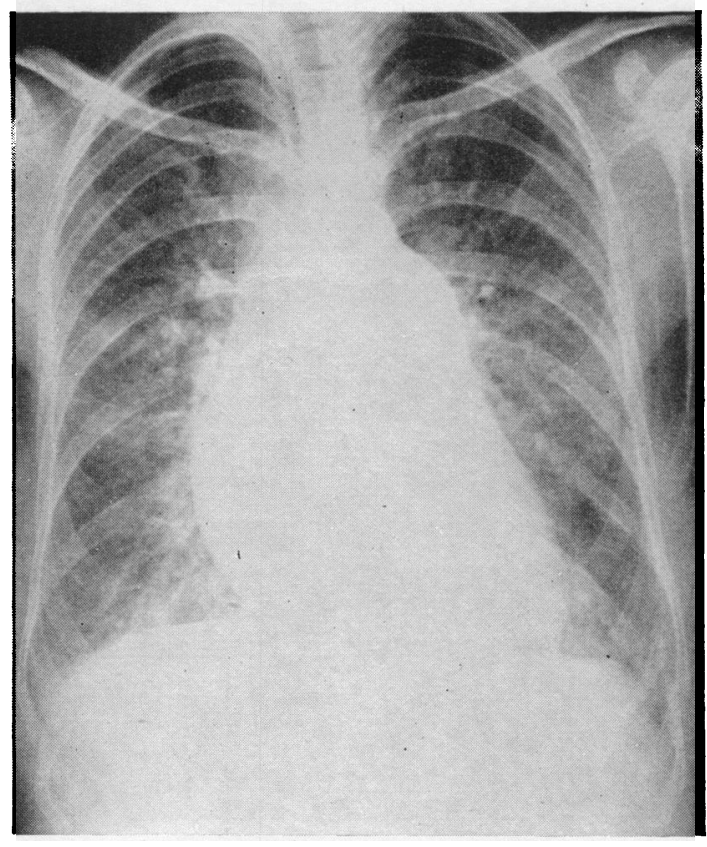

Fig. 15.-Mitral stenosis and pulmonary hypertension, showing great dilatation of the pulmonary trunk, right auricle and superior vena cava, and pulmonary clouding.

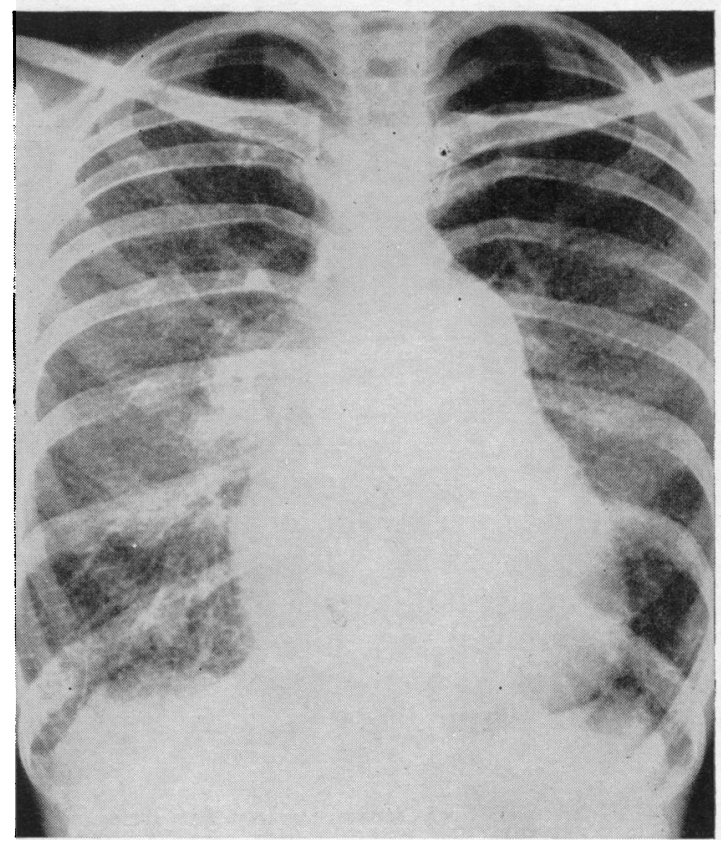

FIG. 16.-Mitral stenosis and pulmonary hypertension, showing great enlargement of the pulmonary trunk and right heart, with pulmonary clouding, interlobular lines and hæmosiderosis.

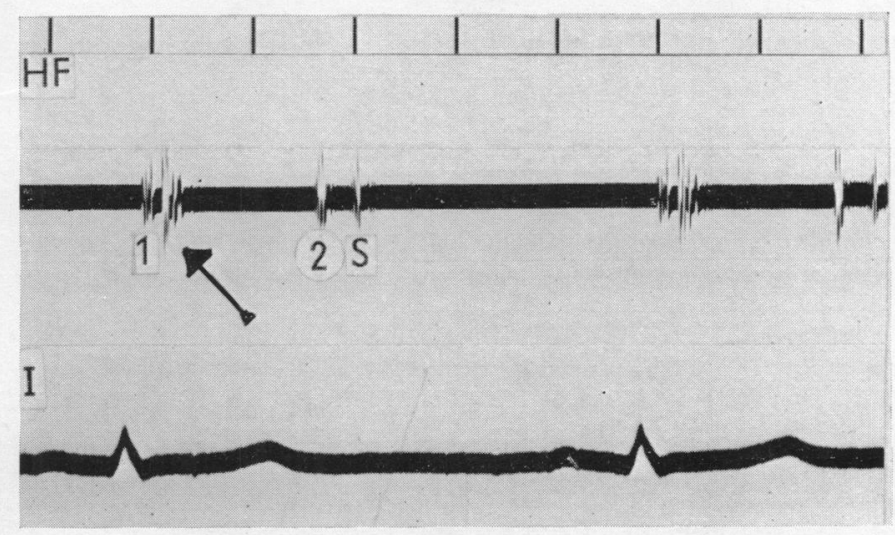

Fig. 17.-Mitral stenosis and pulmonary hypertension. Sound in early systole (arrow). Snap sound (S) in early diastole. No murmurs are present. 
history of rheumatic fever in early life should be sought. If this is forthcoming and particularly if the patient was told at that time that his heart was affected, the presence of mitral stenosis becomes more likely. In other varieties of pulmonary hypertension sinus rhythm is usually preserved, so that if auricular fibrillation is present, as in five of our twelve cases, the association of mitral stenosis with pulmonary hypertension is a strong presumption. The diastolic murmur may disappear (Fig. 17), but the opening snap usually remains and so proves helpful in diagnosis, although rarely a snap sound in early diastole is found in solitary pulmonary hypertension (Evans et al., 1957). When the presystolic and diastolic murmurs are inconstant or absent in suspected mitral stenosis associated with pulmonary hypertension, the diagnosis of myxoma of the left auricle has to be considered.

The electrocardiogram may assist the recognition of mitral stenosis when it occurs in association with pulmonary hypertension by demonstrating either auricular fibrillation or left auricular preponderance. A bifid $\mathrm{P}$ wave, $3.0 \mathrm{~mm}$. high in $\mathrm{CR}_{4}$ or $\mathrm{CR}_{7}$ with a dominant second peak, or a peak interval of $0.04 \mathrm{sec}$. in any lead regardless of voltage (Thomas and de Jong, 1954), indicates left auricular preponderance, and this sign was present in three of our seven patients who remained in sinus rhythm (see Fig. 11 and 12).

The recognition of associated mitral stenosis is also helped by radiological examination of the patient in the oblique positions during a barium swallow, for enlargement of the left auricle confirms the presence of the valvular lesion. Such enlargement, however, is not always noticeable in mitral stenosis, so that a normal left auricular impression in the æsophogram does not exclude the diagnosis.

\section{The Influence of Pulmonary Hypertension on Mitral Stenosis}

Besides modifying the clinical, electrocardiographic, and radiographic signs identified with uncomplicated mitral stenosis, the addition of pulmonary hypertension may influence the course of the illness. A decision on this is needed preparatory to the selection of patients with mitral stenosis who are likely to gain the greatest benefit from surgical treatment, for at present the incidence of pulmonary hypertension is high among those selected for this form of treatment. Thus, 42 out of the first hundred cases so treated at the London Hospital had pulmonary hypertension.

We have gained the impression from reports hitherto published that many share the belief that the pulmonary vascular changes responsible for pulmonary hypertension in mitral stenosis are wholly reversible, and that this favourable outcome can be attained by surgical treatment of the stenotic mitral valve. Thus, Wood (1954) has said that no case of irreversible pulmonary hypertension had yet been encountered. Turner and Fraser (1956) have stated that evidence of right ventricular hypertrophy in the electrocardiogram, associated with signs of otherwise uncomplicated mitral stenosis, is a strong indication for operation. Mackinnon et al. (1956), although admitting that structural changes are probably concerned in the maintenance of pulmonary hypertension, nonetheless believe that the condition is reversible. Indeed, they have insisted that the presence of high vascular resistance should be recognized as an urgent indication for surgical treatment.

The combined arteriographic and histological examination of the pulmonary vasculature in our patients leads to the inescapable conclusion that the gross obstruction within the arterial system that is present in pulmonary hypertension must inevitably affect the prognosis adversely. Such intimal proliferation as we found seemed a progressive rather than a reversible process. In order to test this conclusion it is necessary to compare the post-operative course of patients with and without associated pulmonary hypertension.

There is no doubt that very high pressures may fall to near normal levels. Janton et al. (1956) followed 50 patients four and a half to seven years after valvotomy and found that in those with the highest pulmonary arterial pressures before operation the fall in pressure though gradual was ultimately profound. Thus in one patient, a pressure of $143 / 56 \mathrm{~mm}$. $\mathrm{Hg}$ fell to $36 / 15$; in another a pressure of $130 / 59$ fell to $24 / 8$, while in a third a pressure of $105 / 25$ fell to $23 / 4 \mathrm{~mm}$. $\mathrm{Hg}$. Soulié et al. (1956) studied the hæmodynamic changes following valvotomy in 70 cases of severe uncom- 
plicated mitral stenosis and their findings were similar to those of Janton et al. (1956). Soulié, however, excluded cases regarded as having chronic cor pulmonale secondary to mitral stenosis, having previously emphasized (Soulié et al., 1953) the danger of general anæsthesia in this class of patient.

Baker et al. (1955) followed 45 patients with mitral stenosis for at least three years after valvotomy and concluded that those with severe pulmonary hypertension did well and maintained their improvement. Nevertheless, three of their six patients with mean pulmonary artery pressures exceeding $80 \mathrm{~mm}$. $\mathrm{Hg}$ died following the operation, while among the 39 patients without extreme pulmonary hypertension there were only two immediate deaths.

Mackinnon et al. (1956) reported six cases of mitral stenosis with very high pulmonary vascular resistance and claimed that the pulmonary hypertension was reversible. The results which they publish do not, however, justify this view. Thus, one died of heart failure during medical treatment before the operation could take place. Of the five in whom valvotomy was carried out, one died 12 hours later in spite of good splitting of the valve; another was not improved and the right ventricular pressure had remained at $140 \mathrm{~mm}$. of $\mathrm{Hg}$; in another the pulmonary arterial pressure remained high $(66 / 24 \mathrm{~mm}$. Hg) although the capillary venous pressure had fallen to normal; the fourth case had not been recatheterized and continued to show some incapacity; and in only one was the result excellent.

Ferrer et al. (1955) studied the circulatory effects of mitral valvotomy in 27 patients. Of the 18 with severe pulmonary hypertension, the result was classed as excellent in only seven. Four died during or immediately following the operation, and two were not improved. Donald et al. (1956) recatheterized 28 patients 17 to 51 months after satisfactory valvotomy and found that, although the resting pulmonary artery pressures were reduced in all patients, very few approached normal values.

These reports show that in severe pulmonary hypertension mitral valvotomy may be followed by a considerable reduction in the pulmonary arterial pressure and the vascular resistance, and the fact that this reduction is gradual suggests that certain of the structural changes in the lung are reversible. Frequently, however, the pulmonary vascular resistance changes little in spite of a satisfactory fall in pulmonary capillary pressure and the progression of the disease may be unaffected by the operation.

Disappearance of electrocardiographic evidence of right ventricular hypertrophy following mitral valvotomy has been occasionally reported. In the series of 250 patients reported by Turner and Fraser (1956) 158 were judged to have right ventricular hypertrophy. Following the operation the signs of right ventricular hypertrophy had disappeared in 16 per cent, and had regressed variably in another 24 per cent. Among the 42 patients with mitral stenosis and pulmonary hypertension who underwent mitral valvotomy at the London Hospital, Mounsey (1956) reported that in no instance had the signs of right ventricular preponderance disappeared from the electrocardiogram after what appeared to have been an effective splitting of the stenosed valve. There is conclusive evidence, with which our experience agrees, that in patients with pulmonary hypertension and a greatly reduced cardiac output, the operation itself is a more hazardous undertaking. In such cases the greatest care must be taken in management by physician, anæsthetist, and surgeon, at the time of the operation and during the post-operative period.

\section{The Cause of Pulmonary Hypertension in Mitral Stenosis}

An increase in the pulmonary arterial pressure is inevitable if the circulation is to be maintained in the face of obstruction at the mitral orifice. What is considered here, however, is not this natural rise of pressure, but the more severe and sustained rise that develops in a proportion of patients. Dexter et al. (1950) showed that the immediate cause of this disproportionate pulmonary hypertension was an increased pulmonary vascular resistance, that formed a second barrier to the circulation in the pulmonary vessels in addition to the primary barrier at the mitral valve. 
It might be assumed that this increased resistance would be related to the duration and severity of the mitral stenosis. Wood (1954), however, has shown that patients with pulmonary hypertension are on the average no older than those without, many being in the third and a few in the second decade. In regard to the severity of the stenosis, Becker et al. (1951) found the same high pulmonary vascular resistance in two patients whose dominant lesion was mitral incompetence. Our series has provided a similar example. Again, pulmonary hypertension is not closely related to the level of the pulmonary venous pressure, for Dexter et al. (1950) found that some patients with pulmonary capillary venous pressure in the twenties had much higher vascular resistance than others with a pressure (in $\mathrm{mm}$. of $\mathrm{Hg}$ ) in the thirties.

Opinion on the nature of the abnormal pulmonary vascular resistance in mitral stenosis is divided. It is probably true to say that the majority of workers in this field believe that it arises from pulmonary vasoconstriction. The main evidence put forward in support of this view is that the resistance may sometimes be reduced by the administration of such drugs as hexamethonium (Davies et al., 1954; Wade et al., 1956) and acetylcholine (Harris, 1955; Wood, 1956), and by valvotomy (Wood, 1954; Mackinnon et al., 1956). It is not known with certainty whether the degree of vasoconstriction in patients with pulmonary hypertension is in excess of the physiological vascular tone, and if so what causes it. Wood (1956) maintains his earlier suggestion (Wood, 1952) that in certain subjects vasoconstriction develops in response to pulmonary hypertension itself.

Soulié et al. (1953) found a close parallel between the extent of the lesions in the alveolar septa and the degree of vascular resistance, and suggested that pulmonary hypertension was the result of this reduction in the pulmonary bed. In our series, however, the severity of parenchymal disease in cases with pulmonary hypertension did not appear to be greater than in those without pulmonary hypertension.

Other workers have sought to account for the increased vascular resistance in mitral stenosis on the basis of structural changes in the pulmonary arteries. Edwards (1953) considered that the histological appearances of hypertensive pulmonary vascular disease suggested a persistence of the fotal state of the small pulmonary arteries with subsequent elevation of the blood pressure giving rise to additional arterial changes.

The present investigation has demonstrated that pulmonary hypertension in mitral stenosis is invariably associated with a considerable reduction in the pulmonary arterial bed by structural changes that affect the arterioles and small pulmonary arteries throughout the lungs. These changes are of two kinds. First, the vessels are constricted and indistensible, and secondly they are the seat of intimal proliferation. Any theory that purports to nominate the cause of pulmonary hypertension in mitral stenosis must explain the origin of these structural changes.

The refractory arterial contraction which has in the past been mistaken for hypertrophy of the muscular arteries and muscularization of the arterioles, may be the result of long-continued arterial spasm. If, as Wood (1952) has suggested, these patients react abnormally to a rise in pulmonary arterial pressure by developing vaso-constriction, it is conceivable that this effect may lead ultimately to persistent arterial narrowing.

In regard to the nature and cause of the intimal proliferation, Thomas et al. (1956), failing to find significant correlation between moderate or advanced pulmonary arteriosclerosis and the presence of right ventricular hypertrophy, suggested that the degree of the arterial changes was insufficient to cause a significant increase in the pulmonary vascular resistance. They also concluded that thrombo-embolism was an important factor in the pathogenesis of the abnormal arterial changes. The authors, however, did not give details of the number of histological sections examined in each case nor of the site from which they had been taken; it is possible that sometimes they were not representative of the lungs as a whole.

In 1951 Evans postulated that most forms of pulmonary hypertension start with the presence of congenital deficiencies in the media of the lesser pulmonary arteries. In the presence of a raised pulmonary arterial pressure from any cause, intimal proliferation formed in connection with such deficiencies gives rise to arterial stenosis or occlusion and to pulmonary hypertension. 
In a case of so-called primary pulmonary hypertension, Gilmour and Evans (1946) found innumerable foci of medial hypoplasia or aplasia. Similar foci were present in 9 of the 11 cases of solitary pulmonary hypertension reported by Evans $e$ t al. (1957), and in each of the 12 cases of pulmonary hypertension associated with mitral stenosis described in this paper. This mechanism would explain the more frequent finding of pulmonary hypertension in mitral stenosis than in other conditions, for the considerable rise in pulmonary arterial pressure consequent on the valvular block, acts as a powerful stimulus to the development of intimal proliferation, even in patients in whom medial deficiencies are not abundant.

\section{SUMMARY AND CONCLUSIONS}

The pulmonary vasculature was specially examined at necropsy in 24 patients with mitral stenosis in order to explain the presence of pulmonary hypertension in some and its absence in others.

The pulmonary arteriogram showed two kinds of abnormality, focal and diffuse. The focal changes were common to all cases, but the diffuse changes were only found in those in whom subsequent examination revealed severe arterial disease.

Histological examination likewise showed two kinds of abnormality, subsidiary and salient. The subsidiary changes, which included intimal thickening and thrombosis within the large arteries and subintimal thickening of the venules, were common to all cases. The salient changes, on the other hand, were confined to 12 cases, and consisted of two processes which together led to great narrowing of the arterial bed throughout the lung. First, there was diffuse refractory arterial and arteriolar contraction. Secondly, there was great and widespread intimal proliferation, in which thrombosis with subsequent organization may have played a part, within the arterioles and the muscular arteries under $0.2 \mathrm{~mm}$. in diameter. Associated with the intimal proliferation in the small muscular arteries, there was hypoplasia of the media.

These salient changes were neither related to the degree of mitral stenosis, nor to the age of the patient, but in each of the twelve in whom they were present, there was great hypertrophy of the right ventricle at necropsy. Pulmonary hypertension was diagnosed in these patients during life on the basis of clinical, electrocardiographic, and radiological examination, and without recourse to pulmonary arterial catheterization.

This investigation, therefore, has established that vascular obstruction accounts for persistent pulmonary hypertension in mitral stenosis.

We believe that mitral valvotomy in these cases is unlikely to produce material or lasting benefit, for the arterial changes that they show appear to be progressive and irreversible. If surgery is undertaken, special care is necessary during anæsthesia and the operation.

We are indebted to Dr. D. Evan Bedford for permission to include three of his cases. Dr. Wallace Brigden has helped us with advice, and so has Dr. J. P. D. Mounsey. Professor Dorothy Russell has made available to us the findings at necropsy in many of the cases we describe here.

\section{REFERENCES}

Baker, C., Brock, R. C., and Campbell, M. (1955). Brit. med. J., 2, 983.

Becker, D. L., Burchell, H. B., and Edwards, J. E. (1951). Circulation, 3, 230.

Davis, L. G., Goodwin, J. F., and Van Leuven, B. D. (1954). Brit. Heart J., 16, 440.

Dexter, L., Dow, J. W., Haynes, F. W., Whittenberger, J. L., Ferris, B. G., Goodale, W. T., and Hellems, H. K. (1950). J. Clin. Invest., 29, 602.

Donald, K. W., Bishop, J. M., Wormold, P. N., and Wade, O. L. (1956). Brit. Heart J., $18,566$.

Edwards, J. E. (1953). Congenital Malformations of the Heart and Great Vessels (Section of Pathology). S. E. Gould, Springfield, Ill.

Evans, W. (1951). Proc. R. Soc. Med., 44, 600.

- Short, D. S., and Bedford, D. E. (1957). Brit. Heart J., 19, 93.

Ferrer, M. I., Harvey, R. M., Wylie, R. H., Himmelstein, A., Lambert, A., Kuschner, M., Cournand, A., and Richards, D. W. (1955). Circulation, 12, 7.

Gilmour, J. R., and Evans, W. (1946). J. Path. Bact., 58, 687.

Goodwin, J. F., Steiner, R. E., and Lowe, K. G. (1952). J. Fac. Radiol., 4, 21. 
Harris, P. C. (1955). Ph.D. Thesis, Univ. of Lond.

Heath, D., and Whitaker, W. (1955). J. Path. Bact., 70, 291.

Henry, E. W. (1952). Brit. Heart J., 14, 406.

Janton, O. H., Davila, J. C., and Glover, R. P. (1956). Circulation, 14, 175.

Larrabee, W. F., Parker, R. L., and Edwards, J. E. (1949). Proc. Mayo Clin., $24,316$.

McKeown, F. (1952). Brit. Heart J., 14, 25.

Mackinnon, J., Wade, E. G., and Vickers, C. F. H. (1956). Brit. Heart J., 18, 449.

Mounsey, J. P. D. (1957). Personal communication.

O'Neal, R. M., Thomas, W. A., and Hartroft, P. M. (1955). Arch. Path., 60, 267.

Parker, F., and Weiss, S. (1936). Amer. J. Path., 12, 573.

Posselt, A. (1909). Ergebn. allg. Path. path. Anat., 13, 298.

Short, D. S. (1955). Brit. Heart J., 17, 33. (1956). J. Fac. Radiol., 8, 118.

Soulié, P., Baillet, J., Carlotti, J., Chiche, P., Picard, R., and Serville, M., Voci, G. (1953). Arch. Mal. Caur, $46,393$.

- Joly, F., Carlotti, J., and Sicot, J. R. (1956). Arch. Mal. Ceur, 49, 729.

Thomas, P., and De Jong, D. (1954). Brit. Heart J., 16, 241.

Thomas, W. A., Lee, K. T., and Rabin, E. R., O'Neal, R. M. (1956). Arch. Path., 62, 257.

Turner, R. W. D., and Fraser, H. R. L. (1956). Lancet, 2, 525 and 587.

Wade, E. G., Mackinnon, J., and Vickers, C. F. H. (1956). Lancet, 2, 18, 458.

Wood, P. H. (1952). Brit. med. Bull., 8, 348.

- (1954). Brit. Med. J., 1, 1051 and 1113.

(1956). Disease of the Heart and Circulation. Eyre and Spottiswoode, London, 2nd ed. 